\title{
Chapter 7 \\ Descartes on the Theory of Life and Methodology in the Life Sciences
}

\section{Karen Detlefsen}

\begin{abstract}
As a practicing life scientist, Descartes must have a theory of what it means to be a living being. In this paper, I provide an account of what his theoretical conception of living bodies must be. I then show that this conception might well run afoul of his rejection of final causal explanations in natural philosophy. Nonetheless, I show how Descartes might have made use of such explanations as merely hypothetical, even though he explicitly blocks this move. I conclude by suggesting that there is no reason for him to have blocked the use of hypothetical final causes in this way.
\end{abstract}

Keywords Descartes $\bullet$ Teleology $\bullet$ Methodology $\bullet$ Hypotheses $\bullet$ Nature of life

Descartes was a practicing natural philosopher. His areas of research included a specific interest in investigating the phenomena of life. He treated human, animal, and plant bodies as distinctive kinds of bodies, and he afforded them separate scientific $^{1}$ treatment, both in practice and in his written work. On 18 December 1629, he wrote to Mersenne that he was beginning a study of anatomy (AT I, 102) ${ }^{2}$, by which he meant the anatomy of living bodies. The fruits of his anatomical and physiological investigations appeared in various written forms throughout his life, including Traité de l'homme (hereafter Treatise), the fifth part of Discours de la méthode (Discourse), a planned but unwritten fifth section of the Principia Philosophiae (AT VIIIa, 315/CSM I, 279; Principles), the first 16 articles of Part I of Passions de l'âme (and various comments scattered throughout the remainder of that text; Passions), La Description du corps humain (Description) which also deals with

\footnotetext{
${ }^{1}$ I use the term "science" and its cognates for ease of expression, mindful of the fact that our meaning of the term most closely aligns with Descartes' "natural philosophy".

${ }^{2}$ I use the following abbreviations to refer to editions and translations of Descartes' works: AT=Descartes 1964-76; CSM=Descartes 1985a; CSMK=Descartes 1985b; SV=Descartes 1989; SG=Descartes 1998 .

K. Detlefsen $(\bowtie)$

Department of Philosophy, University of Pennsylvania, Philadelphia, PA, USA

e-mail: detlefse@sas.upenn.edu
} 
animal and plant bodies, Primae cogitationes circa generationem animalium (Generation), Excerpta anatomica (Excepts), and assorted letters.

Given this, we can expect that Descartes conceives of living beings as distinct from non-living beings in some way or another. For if this were not true, then Descartes would have no way of isolating a class of bodies taken to be living bodies, and he would then not be able to identify any individuals to serve as the subject matter of the life sciences - sciences to which he devoted considerable professional time. And this would render incoherent this aspect of his life as a working natural philosopher. Moreover, he explicitly does acknowledge life as a category. In a letter to Regius of June 1642, for example Descartes talks of many sorts of bodies as machines, but he nonetheless makes distinctions within the broader class of machines, ${ }^{3}$ and isolates those that are living from the rest (AT III, 566/CSMK 214). He also acknowledges the category of life in other texts. For example, he planned (though never wrote) a fifth section of the Principles devoted to "living things, i.e. animals and plants" (AT VIIIa, 315/CSM I, 279), and one can effectively argue that Descartes includes the human body among those that are living given his recognition that human bodies and animals perform many of the same sorts of actions (AT III, 121/CSMK 149), including those detailed in his writings on animals. He also makes a clear distinction between the machines we can build and living machines when he emphasizes that we could never make ourselves a new body because we could never make the matter out of which our bodies are constructed (AT VI, 148).

But there are two difficulties Descartes faces in identifying a separate class of living beings, and both stem from the fact that, for him, metaphysics is ontologically prior to both physics and what we might call the "special sciences". ${ }^{4}$ Recall his famous "tree of philosophy" with metaphysics as the roots, giving rise to and placing constraints on physics as the truck, which in turn gives rise to and places constraints on the special sciences, "which may be reduced to three principal ones, namely medicine, mechanics, and morals" (AT IXb, 14/CSM I, 186). There are two aspects of Descartes' metaphysics that cause him potential difficulties in identifying a class of living beings to serve as the subject matter of the life sciences. The first is his austere ontology of the created world, according to which there are just two kinds of substances, material substance (with the essence of extension) and souls (unextended things with the essence of thought). The second is his conception of God's nature and our relationship with him, specifically that fact that we do not have cognitive access to God's ends, or the purposes that guided him in the creation of the material world.

\footnotetext{
${ }^{3}$ On the meaning of "machine", specifically with respect to Descartes' medical philosophy, see Manning 2012.

${ }^{4}$ See Hatfield 1993 and Garber 1992, 13 for this account of the relation between metaphysics and physics. A different way of thinking about the relation between metaphysics and physics is put forth by Stephen Gaukroger who holds that "there was nothing internal to Descartes' project of natural philosophy that required metaphysical foundations, and there was nothing crucial to his natural philosophy that could only be generated from such metaphysical foundations" (Gaukroger 2002, 1-4). I leave aside these two competing visions of the relation between metaphysics and physics, since this debate does not impact my current project.
} 
The first aspect of Descartes' metaphysics noted above leads to the first hurdle in identifying a class of living being - the easier hurdle to overcome. Because he rejects the notion of natural essences beyond material substance as extension and immaterial thinking souls, he loses the ability to ground universals or natural material kinds in the ontology of the world. With every material body having the same essence as every other material body, there appears to be nothing in the nature of bodies themselves that identifies them as distinct kinds of bodies worthy of distinct scientific treatment. Indeed, according to this line of argument, there are exactly two natural kinds in the world - embodied souls, for souls cannot non-miraculously exist without human bodies (AT III, 461/CSMK 200) - and all non-ensouled material bodies. So there can be a science of human beings grounded in a distinct ontology, but no other special science grounded in a distinct ontology. ${ }^{5}$ Descartes' ontology thus permits special, scientific treatment of only the human being, but not of the living body. But this is a problem for Descartes given that he includes animal and plant bodies with human bodies in his anatomical and physiological writings. In the first section of this paper, I develop what I think should have been Descartes' theoretical conception of life. In doing so, I show that Descartes does not eliminate the class of living bodies from his natural philosophy even while his austere ontology of material substance does result in the ability to explain the phenomena of all living bodies in terms of matter in lawful inertial motion; that is he is a reductionist with respect to explanation of life phenomena but not an eliminativist with respect to life itself $^{6}$ - much as we are today, albeit with a more sophisticated science at our disposal.

Providing a solution to the first problem just noted feeds directly into the second problem. For the theoretical account of living beings that I think Descartes must be - and implicitly is - committed to relies upon making claims to God's ends or purposes vis a viz the created material world. But this flies in the face of the second aspect of his metaphysics noted above, specifically that we cannot know any of God's ends with respect to his creation of the material world, and so we cannot rely upon knowledge claims regarding those ends in natural philosophy. ${ }^{7}$ I think this problem is surmountable given resources Descartes has within his natural philosophy, and I show (in Parts 2-4 of this essay) how Descartes could have overcome this difficulty had he called upon these resources. I am particularly interested in showing: (a) that there is a way of attributing weak sorts of internal ${ }^{8}$ ends to material bodies

\footnotetext{
${ }^{5}$ Stephen Menn $(2000,139-41)$ and Dennis Des Chene (2001, 30, 62 and 64) both suggest that this may well follow from Descartes' ontology.

${ }^{6}$ On this point, see Gaukroger 2000 and 2010. T.S. Hall (1970, 55-56) also points to the fact that Descartes provides reductionist explanations, and while Hall does not explicitly mention that Descartes does not thereby eliminate the category of life altogether, it is strongly implicit in his discussion of Descartes' account of living bodies.

${ }^{7}$ For a few of the many articles on Descartes' ideas on final cause in natural philosophy, see Brown 2013; De Rosa 2007; Detlefsen 2013; Distelzweig 2015; Hatfield 2008; La Porte 1928; Schmaltz (manuscript); and Simmons 2001.

${ }^{8}$ I avoid the use of "intrinsic" and "extrinsic", using "internal" and "external" instead to avoid the technical meaning of the former pair in Descartes" philosophy. See Manning 2012 and Manning forthcoming. I engage with Manning's discuss of intrinsic and extrinsic denominations in Sect. 7.3 below when I expand on what I mean by "internal ends" in Descartes.
} 
considered not in terms of their metaphysical essence but rather in terms of their built structures; and (b) that Descartes' own friendliness to hypotheses in natural philosophy could have allowed him to appeal to such internal ends (even though he explicitly blocks this move).

In the process of completing this work, I aim to underscore Descartes' role in two historical trends that are especially interesting in the history of the life sciences. First (only implicit in Descartes), once Aristotelian substantial forms are ousted from an account of living bodies by mechanists such as Descartes, there appears to be no easy way to ground ends within the nature of wholly material bodies. And yet, pre-theoretically, and in accordance with common sense, built machines must have some sort of end internal to them; Aristotle implicitly acknowledges this, even with respect to artifacts, and it is implicit in Descartes' writings too. The crucial difference is that Aristotelianism has the ontology to account easily for this while it is less clear how this teleology can be accommodated on a Cartesian ontology. Second, in scientific epistemology, there is the emergence of a respectable category of the probable according to which the probable is not automatically associated with the merely speculative. This category is associated with the use and testing of hypotheses, and Descartes himself embraced the use of hypotheses, and thus embraced (however uneasily) the category within scientific epistemology of the respectably probable. He just didn't capitalize on his embrace of this trend as fully as he might have in his life sciences.

Before starting the main work of this paper, I make the following two preliminary points. First, there are two distinct theories of the origins of living bodies to be found in Descartes' corpus. One is the idea that living forms emerged from an initial chaos through non-purposeful motion of that material chaos (e.g. VI: 42/CSM I, 132; XI: 34-5/ CSM I, 91; and VIIIa: 102-3/ CSM I, 257). ${ }^{9}$ The other is the idea that God formed those beings. In this paper, I proceed on the assumption of the latter idea, even while I think there is much promise in Descartes' chaos idea. Dealing with the chaos theory is work for elsewhere.

The second preliminary point is that I propose we think about Descartes' general approach to the life sciences in the follow way. Dennis Des Chenes' insight expressed thus is helpful:

\footnotetext{
No doubt some sort of distinction between living and nonliving things comes to us early in life. In every human culture the classification of things into living and nonliving is among the most basic. Though some judgments have changed, Aristotle's division between living and nonliving, those of Aristotelian authors, Descartes', and our own, overlap a great deal. But broad agreement on the domain of life coexists easily... with grossly dissimilar concepts of life. The list of things that Hobbes, Descartes, and Regius would call plants and animals differs little from the lists that Toletus, Suárez, or Eustachius would give. The concept of the living in the new philosophers, on the other hand, differs as greatly from the Aristotelians' as do their concepts of body and natural change. ${ }^{10}$
}

\footnotetext{
${ }^{9}$ For a discussion of some of the material I cover herein with the chaos theory in mind, see Hatfield 2008.

${ }^{10}$ Des Chene 2000a, 20.
} 
Descartes' own way of proceeding as a natural philosopher seems to follow the general approach captured by Des Chene. First, Descartes pre-theoretically identifies the domain of the living. Second, he then subjects the individuals within this domain to scientific investigation. The investigations may well problematize pretheoretical intuitions about what does and does not fall into the domain of the living - as it does for working scientists today. But the first two steps do seem to capture Descartes' actual approach as a working life scientist. Further, it is clear what Descartes takes to be the items that serve as the subject matter of the life sciences: plants, animals, and human bodies considered (counterfactually) in isolation of their souls. ${ }^{11}$ These are the bodies that he implicitly identifies as living when he studies these and only these in his active scientific practice and in his theoretical biological ${ }^{12}$ writings. He also explicitly identifies animals and plants as living, and he does so within the context of his treatment of human bodies indicating that the latter are living too. In the Description, for example, he is explicit that human bodies, animals, and plants should be categorized together as living when, for example, he extends his discussion of nutrition beyond the human: “...we must bear in mind that the parts of those living bodies that are maintained through nourishment, that is, animals and plants, undergo continual change..." (XI: 247/ CSM I, 319; emphasis added). The domain of life, then, includes all and only plant, animal and human bodies. My task now is to reconstruct a theoretical account of life that is consistently capable of picking out all and only members of this domain, and that is consistent with Descartes' texts and own conceptual commitments, including the metaphysics that is at the foundations.

\subsection{Descartes' Conceptions of Life}

Ann Wilbur MacKenzie is right when she proposes that "Descartes did not provide any systematic and general analysis of ' $\mathrm{x}$ is alive" ", ${ }^{13}$ because he did not abstract sufficiently enough from his specific claims about individual living beings to derive a general theory. Still, as she and others have shown, it is possible to infer a number of different possible conceptions of life, which Descartes may have embraced. In this section, I draw upon the insights of MacKenzie and others who bring some elements of Descartes' conception of life to our attention. ${ }^{14}$ I consider three possible

\footnotetext{
${ }^{11}$ Given my focus on the human body, along with other non-ensouled living bodies, my project departs somewhat from a project that focuses exclusively on medical philosophy to the extent that the latter is a field concerned with the health and illness of human beings.

${ }^{12}$ As with my use of "science", I use the term "biology" mindful of the fact that this term and the cluster of sciences we now recognize by this term did not emerge until the late eighteenth century. I use this for ease of expression to capture Descartes' writings about living bodies.

${ }^{13}$ MacKenzie 1975, 2-3.

${ }^{14}$ Ablondi 1998; Bitbol-Hespériès 1990; Canguihelm 1965; Distelzweig 2015; Des Chene 2000b; and Shapiro 2003.
} 
theories of life for which there is textual evidence in Descartes' corpus. I show that all three capture crucial elements of the theoretical account of living bodies to which I believe Descartes must have been committed.

\subsubsection{Living Bodies as Those with Heat as Their Corporeal Principle of Action ${ }^{15}$}

In a letter to Henry More of 5 February 1649 Descartes writes: "I do not deny life to animals, since I regard it as consisting simply in the heat of the heart..." (AT V, 278/ CSMK 366; c.f. AT IV, 686; AT XI, 226/CSM I, 316; AT XI: 333/SV 23; AT XI 407/SV 76-7). Since this is the most explicit statement regarding the principle of life to be found in Descartes, it is tempting to simply take Descartes at his word and accept this as the defining criterion of life.

But this criterion will not serve the purpose for it cannot unfailingly pick out all and only living bodies. Some of the apparent difficulties with this criterion are surmountable with a large dose of charity in interpretation, but not all the difficulties can be overcome. First, while Descartes locates this heat in the heart of the living organism, it is not clear that all living organisms have hearts; plants are the clearest case. ${ }^{16}$ Still, one may salvage the heat criterion by acknowledging that Descartes also allows for heat generally conceived (and not located in any specific organ), to act as the principle of life since he also says that it is the principle common to animals, plants, and human bodies (letter to Mersenne: AT III, 122/CSMK 149), even before any organs, including the heart, have begun to form at all (AT XI, 534). But, and second, one may object to the claim that all organisms are in fact hot, and again plants are an obvious example as are cold-blooded animals. Descartes explicitly faces this objection. In response to Plempius' claim that fish do not have hot hearts (AT I, 498), Descartes responds that "although we do not feel much heat in fish, their hearts feel hotter than all other organs in their body" (AT I, 529/CSMK 83; c.f. AT II, 66/CSMK 94-5). Likewise, he takes the heat found in animal hearts to be analogous to the heat in hay before it dries (AT XI, 121/SG 100 and 254/CSM I, 322; AT VI, 46/CSM I, 134), and charitably read, this can be taken as a case of plants so newly cut as to retain some vestige of life (namely, heat). More explicitly, Descartes claims that tree bark and fruit (presumably both examples of plant life) can exude vapors due to their internal heat (AT II, 67/CSMK 95-6). Whatever the empirical validity of these observations, it is clear that Descartes wishes to extend heat to all human, animal, and plant bodies seemingly in order designate them all as living machines.

The heat criterion, however, is not an adequate principle of life because it allows too many individuals into that category. Fred Ablondi draws our attention to this

\footnotetext{
${ }^{15}$ Bitbol-Hespériès 1990, passim takes heat as Descartes' theory of life.

${ }^{16}$ This is MacKenzie's (1975, 3-5) objection to the conception of life as heat in the heart. Ablondi $(1998,181)$ makes this objection too.
} 
difficulty, noting the problematic case of the steam engine. ${ }^{17}$ Similarly damaging are Descartes' own examples, such as when he likens the heat found in living bodies to that which occurs during the fermentation of wine (AT XI, 254/CSM I. 322), indicating that this heat is also found in the nonliving. Heat from a fire without light, then, is consequently not up to the task of identifying all and especially only members of the class of living machines since it is also found in some non-living bodies and processes as well.

One may wish to take this as evidence that there is, in the final analysis, no clearly delineated category of living bodies for Descartes given his explicit association of heat with life. ${ }^{18}$ I resist this conclusion, for we must pay heed to Descartes' own words and practice, acknowledge that he is committed to a science of life, and therefore acknowledge the need for the category of life. Consequently, we must dismiss the "heat without light" candidate as a viable one for Descartes' theory of life.

\subsubsection{Living Bodies as God-Made Machines with a Complexity Specific to Them}

Less explicit than the heat criterion is the suggestion that living bodies are machines made by God and thus have a kind of complexity that distinguishes them from nonliving machines. Here are two texts suggesting this conception:

Those who know how many kinds of automata, or moving machines, the skill of man can construct with the use of very few parts, in comparison with the great multitude of bones, muscles, nerves, arteries, veins and all the other parts that are in the body of any animal.... will regard this [animal] body as a machine which, having been made by the hands of God, is incomparably better ordered than any machine that can be devised by man, and contains in itself movements more wonderful than those in any machine made by man (AT VI, 55-6/ CSM I, 139).

And:

We see clocks, artificial fountains, mills, and other similar machines, which, even though they are only made by men, have the power to move of their own accord in various ways. And, as I am supposing that this machine [made with the explicit intention of being as much like us as possible] is made by God, I think you will agree that it is capable of a greater variety of movements than I could possibly imagine in it, and that it exhibits a greater ingenuity than I could possibly ascribe to it.

I shall not pause to describe to you the bones, nerves, muscles, veins, arteries, stomach, liver, spleen, heart, brain, not all the other different parts from which this machine must be composed, for I am assuming that they are just like those parts of our own bodies having the same names.... [S]o that it remains only for me to explain these movements [that depend upon the parts] to you here in the proper order and by these means to tell you which of our functions these represent. (AT XI, 120-1/CSM I, 99)

\footnotetext{
${ }^{17}$ Ablondi 1998, 183.

${ }^{18}$ See Bitbol-Hespériès 1990, 71.
} 
There are a number of ways of interpreting this criterion. Certainly, there seem to be two central features of it: living machines are "incomparably better ordered" and so exhibit "a greater ingenuity" than is to be found in non-living machines such as those made by humans; and living machines are "made by the hands of God". The first feature just noted might be interpreted in one of two ways: living bodies might have a degree of complexity that far surpasses that of non-living bodies; or they might have a kind of complexity far superior to any that a human could achieve when building a machine.

Locating the source of the uniqueness of living bodies in a difference in degree is suggested in the first passage where Descartes refers to human-made machines as having "very few parts" in comparison with God's machines. This is a promising route to take, especially for a theologically minded philosopher of the seventeenth century. For one might claim that the difference in kind between living and nonliving derives from a difference in degree between infinitely complex living bodies (that only an infinitely capable builder, i.e. God, could make) and merely finitely complex non-living bodies (that humans may well be capable of making). This will be one way through which both Malebranche and Leibniz secure the distinction between living and non-living. But it is not Descartes' way for he is reluctant to associate the infinite with anything other than God himself (e.g. AT VIIIa, 14-15/ CSM I, 201-202). According to Descartes, God's machines are only "incomparably" better ordered. Perhaps, then, Descartes believes that living bodies are complex enough (but not infinitely so) to demarcate living bodies. While this accords with Descartes' own position on the infinite, it fails to secure a conception of life. For without the difference in degree being a difference between the finite and the infinite, there can be no decisive difference in kind. Somewhere along the continuum of increasingly complex machines, a line is supposedly crossed that demarcates the living from the non-living, but it is not clear where this line lies such that a principled distinction can be drawn. ${ }^{19}$ Maybe Descartes could shore up this second approach by saying that what makes living bodies unique is not simply that they have an incomparable (though not infinite) degree of complexity, but that they have this due to their having been made by God. But this will not suffice, for God made many other machines besides living bodies, and so we must still be able to distinguish between his living and his non-living machines. But then the burden for this distinction must fall somewhere, and, once again, an incomparable yet not infinite degree of complexity is not up to the task of doing the work necessary to make the distinction.

So perhaps Descartes' intention is to locate the source of the uniqueness of living bodies in a special kind of complexity found in God-made living machines that is

\footnotetext{
${ }^{19}$ Thomas Fuchs makes this point $(2001,125)$. Genevieve Rodis-Lewis (1978) approaches this point too when considering AT II: 525 which allows that crystals may have a middle nature between living and non-living. It may be possible for Descartes to tolerate these grey areas in the same way that we tolerate difficult cases that seem to straddle the life-nonlife divide (such as viruses), but there is no need for this since there is a better theory of life forthcoming which does not require Descartes to accommodate the sort of grey area identified here.
} 
not shared by any other machines, God-made or other. This does seem to capture better Descartes' intention as articulated in the texts above. Then the obvious question arises: what is that special kind of complexity in structure that God has made that can demarcate the living from the non-living? The texts cited above offer two answers. According to one answer, living bodies have a "great multitude" of certain kinds of parts in common (also, probably, disposed to one another in certain ways): hearts, arteries, livers and so forth (as Descartes lists in the passages above). The second passage cited is dealing with the supposed replica of a human body that Descartes is asking the reader to imagine. As human, the list of very specific body parts offered as unique to such a body makes sense. The first passage is more troublesome, however, for that passage is meant to apply to the body of "any animal", and it is not immediately clear that all animals (monkeys, turtles and oysters alike) possess the same collection of body parts. Moreover, if we were to take this conception to be the theoretical conception of life Descartes is committed to, then it would have to apply equally to plants as well as to animal and human bodies. But on the face of it, plants do not have hearts or livers or spleens or bones. ${ }^{20}$ So prima facie, a special kind of complexity that identifies specific body parts as necessary to that complexity, is not adequate as a conception of life since it cannot reliably pick out all members of the domain of life. ${ }^{21}$

According to the second answer to the question "what is that special kind of complexity in structure that God has made that can demarcate the living from the non-living?", living bodies have the sort of structure - including the sorts of body parts - that can permit "movements more wonderful than those in any machine made by man". This answer certainly makes reference to the structure, but the structure remains entirely abstract ${ }^{22}$ - a living body's structure is whatever structure is necessary to give rise to specific, wonderful movements, and many, diverse structures might fit that bill. Additionally, in this answer, the structure is subordinate to and in service of the life-specific functions or behaviors of the body. And it is these functions or behaviors, which do the real conceptual work in distinguishing the living from the non-living; the abstract structure is only a means to the definitive functions. So this second answer is really a third and distinct conception of life: living bodies are those that behave or function in specific ways. I turn to this third, extremely promising, conception shortly. ${ }^{23}$

So, as with the heat theory, the present theory of life fails to identify all and only living bodies in a reliable and principled fashion. Taken as a theory about the degree of complexity of structure, this theory fails for there is no way to establish a difference

\footnotetext{
${ }^{20}$ There were attempts in the early modern period to find structural equivalents of major organs across all living beings, including plants. The fact of these attempts might blunt the current criticism somewhat. See Delaporte, François [1979] 1982.

${ }^{21}$ See Des Chene 2001, 54ff for difficulties in identifying parts in Descartes.

${ }^{22}$ This is MacKenzie's point. She holds that one causal component in Descartes' definition of life must be this fully abstract structural complexity, which permits the behaviors definitive of living bodies (MacKenzie 1975, 9).

${ }^{23}$ See Ablondi 1998 for an enlightening discussion of the structural complexity criterion.
} 
in kind between living and non-living without recourse to an infinitely complex body. And taken as a theory about the kind of complexity, where reference to specific body parts is essential to that theory, it once again fails because it cannot pick out all and only members of the domain of life given the immense diversity in the parts of different living bodies. And so this second theory by itself, cannot be Descartes' considered theoretical conception of life.

\subsubsection{Living Bodies as Machines that Function in Ways Unique to Plants, Animals, and Human Bodies}

As Descartes' experiments and writings on living bodies suggest, the behaviors or activities of life are more or less those that Aristotle associates with the vegetative soul and some of those Aristotle associates with the sensitive soul. The most general functions associated with all living bodies (e.g. AT XI, 202/CSM I, 108; AT I, 263/ CSMK 40) are foetal formation (or generation), growth (which includes transformation as opposed to mere accretion of matter [XI: 596-87]), nutrition and self-maintenance, reproduction, and response to the surrounding environment; in animals, this ability to respond to the environment includes the abilities to sense, remember, and learn in so far as these psychological abilities are conceived of solely in corporeal terms (e.g. AT VII, 436/CSM II, 294; AT X, 416/CSM I, 43; AT III, 433-34/CSMK 196; and Passions passim when Descartes discusses habituation).

MacKenzie includes life functions as one among a few that together make up Descartes' complex theory of life in her view, which includes both causes and effect. "A creature is alive if and only if it has some principle of motion (or other) which, together with some arrangement of parts (or other), enables that creature to engage in some set of activities (or other) which in turn enable that creature to carry out a set of life functions". ${ }^{24}$ The life functions she recognizes are nutrition, growth and generation, and all living bodies display these functions. She also recognizes more determinate activities that only specific kinds of living beings exhibit as contributing to the more general life functions. Examples of these more determinate activities (e.g. in animals with hearts) might include digestion, the heartbeat, and respiration..$^{25}$ According to MacKenzie's approach, then, an adequate account of life must make reference to two causes - a principle of motion (such as heat), and a suitable disposition of organic parts - and a complex of effects - specific behaviors unique to a sub-class of living machines (e.g. animals with hearts) that give rise to general life functions, exhibited by all and only living machines. Heat, then, is better seen as the principle of motion within living bodies, and not the principle of life itself, an option Descartes explicitly offers in the Passions: "While we are alive there is a continual heat in our hearts, which is a kind of fire that the blood of

\footnotetext{
${ }^{24}$ MacKenzie 1975, 10.

${ }^{25}$ Ibid. 8-9.
} 
the veins maintains there. The fire is the corporeal principle underlying all the movements of our limbs" (AT XI, 333/SV 23).

Recently, Distelzweig has provided another distinction that can help fill out Descartes' conception of life, a distinction derived from the historical medical context in which Descartes was writing. Specifically, Distelzweig notes that the

medical tradition employs functio... to refer to and categorize a familiar, long established set of characteristic activities of living things. Usus, in contrast, refers to the contribution a part of activity makes to the exercise of some functio. Both parts and functiones have usus. The usus of a part is the contribution it makes to the exercise of some functio. The usus of a functio, in turn, is the contribution that functio makes to some larger or more fundamental functio, terminating ultimately in the list of main natural, vital and animal functiones. ${ }^{26}$

The distinction that Distelzweig draws our attention to focuses on the hierarchical nature of usus and functio, while MacKenzie's distinction between life behaviors and life functions focuses on the differences between activities that a sub-class of living beings exhibit and activities exhibited by all living bodies. But they can be related to one another precisely because more localized parts and activities often tend to be unique to sub-classes of living beings, as Mackenzie's specific examples underscore.

These basic distinctions seem right to me, though I differ from MacKenzie on a few points. First, I specify that growth is of a specific form, namely growth with bodily transformation - most notably the constant turnover of constitutive matter and not mere growth by aggregation. In the Description, for example, Descartes writes: "we should bear in mind that the parts of all living bodies which require nutrition to sustain them (that is, animals and plants) are continually undergoing change" (AT XI, 247/CSM I, 319). Importantly, once foetal formation is complete, the visible organic structure is maintained despite the constant change in the subvisible constitutive matter of organisms. Today, of course, we call this process metabolism, and it is crucial to the enduring health and survival of living bodies. No other bodies grow in this fashion; it is a form of growth unique to plants, animals and human bodies.

Further, I include two more elements in the list of life functions beyond the three identified by MacKenzie (i.e. nutrition, growth, and generation). These are, first, the ability to react to the surrounding environment (including animals' abilities to sense, remember and learn considered as material, and not mental, processes) and, second and related, the ability to maintain the unified structure of the body despite the wear and tear that follows from interaction with the surrounding environment. Lisa Shapiro identifies these elements as providing a promising non-teleological criterion of health for both human bodies and animals - specifically, she claims that human bodies and animals have integrated structures that are stable and able to preserve themselves. Moreover, she connects staying healthy with the fact of a body's being and staying alive. So I take it that she would endorse this criterion as a necessary component of Descartes' conception of life. Distelzweig (2015), too, accepts this account of life, emphasizing the self-stabilizing aspect of all and

${ }^{26}$ Distelzweig 2015. 
only living beings, which is presumably captured by Shapiro's mention of self-preservation. ${ }^{27}$

These additions are significant for they indicate a crucial aspect of Descartes' theory of life: living bodies perform their activities (e.g. digestion) to contribute to life functions (e.g. growth with transformation) which helps them achieve the further goal of self-maintenance of a unified structure of inter-related parts. This self-maintenance, in turn, permits the continuation of the life-specific behaviors and functions. So in addition to the sub-processes of localized parts within a specific subset of kinds of living bodies, which contribute to the most general, whole-body functions of all living bodies, I propose that Descartes' conception of living bodies includes, as Shapiro notes, the further element of self-maintenance of a unified structure of inter-related parts - or, more familiarly, self-preservation. Indeed, the other behaviors of living beings all contribute to this ultimate, most general behavior.

There is evidence that Descartes takes the self-maintenance of a unified structure adequate to permit continuing self-maintaining activities as a defining feature of living bodies. In Passions, for example, Descartes writes: "For the [human] body is a unity which is in a sense indivisible because of the arrangement of its organs, these being so related to one another that the removal of any one of them renders the whole body defective" (AT XI, 351/SV 35). Once this removal of an essential organ happens, death occurs (AT XI, 330/SV 21). Similarly, in Treatise, Descartes suggests that the living human body forms an integrated whole which, because of its "good condition" of parts into a whole, is able to maintain that whole from disintegrating (AT XI, 143-44/CSM I, 102-3; c.f. AT VIIIa, 318/CSM I, 282; and AT VI, 153). Such passages indicate that the proper dispositions of parts to one another form a structurally integrated whole - what Des Chene calls "dispositional unity". ${ }^{28}$ This whole of parts properly disposed to one another permits the machine to function in specific ways, which further allow it to maintain a stable structure, which is tantamount to engaging in self-preservation. ${ }^{29}$ Notice that Descartes' emphasis in the Passions quotation is on the human body, and so nothing turns on the presence of a soul. As a result, claims he makes here are equally relevant to other living bodies in so far as they exhibit a similar unified arrangement of parts. These passages suggest that living machines could be those that are able to maintain a unified structure of essential organic parts, and that they are able to do so through an internal principle of motion. Crucial to this account of life is the fact that living bodies are able to maintain their unified structure through their own functions, and do not require the interference of an external builder to maintain that structure.

Living machines, therefore, are distinguished from non-living machines as follows. First (as with MacKenzie), I believe Descartes must appeal to both causes and effects in his account of what makes a body a living body. There are two causes one can find in Descartes' texts (these are the two criteria Ablondi takes as necessary and sufficient for demarcating the living in Descartes). The first cause is that living

\footnotetext{
${ }^{27}$ Shapiro 2003, 433-434, including footnote 34.

${ }^{28}$ Des Chene 2001, $125 \mathrm{ff}$.

${ }^{29}$ Shapiro 2003, passim.
} 
bodies have their own internal source of motion, and given a charitable interpretation of Descartes' own texts, this is the heat produced (even in plants) by rapidly moving particles. The second cause is that living bodies have a unique kind of God-made complexity. As with MacKenzie, I believe this complexity must be conceived of abstractly, and it is simply any kind of complexity that permits a specific collection of effects. And so, the effects are as follows. As with MacKenzie and Distelzweig (and bringing their two insights together), specific subclasses of living bodies engage in specific activities, which are often confined to local parts and processes. These are necessary preconditions for, and contribute to the more general, often whole-body, life functions that all plants, animals, and human bodies engage in. These life functions are nutrition, growth, and generation (as with MacKenzie though growth is of a unique kind whereby the body transforms as it grows), as well as the ability to respond to the environment, and the ability to maintain the complex structure of the body in the face of some wear and tear. Taken together, these abilities contribute to the ultimate living function of self-preservation or self-maintenance of a stable structure (Shapiro), which in turn permits the continuation of the activities and life functions identified above.

I ought to underscore one final point about these living machines. Descartes expects - and even goes to considerable lengths in order to try to realize this expectation - that all these elements of living bodies can be fully explained in terms of bits of matter-as-extension within living bodies moving according to simple laws. That is, he fully expects us to give reductionist explanations of living phenomena, but this does not amount to the elimination of the category of living beings. Descartes' austere ontology of the material world allows these powerful mechanical explanations within the life sciences, but does not thereby threaten the life sciences by stripping them of a subject of study. The first problem mentioned at the outset of this paper is thus resolved.

There are significant difficulties for a Cartesian metaphysics with this conception of life. One, which I shall not address here, concerns issues in the metaphysics of individuation. In brief, Descartes' own strict criterion of individuation of physical bodies as found in the context of his discussion of motion at Principles II, 25 (AT VIIIa, 53-4/CSM I, 233) does not permit the constant flux of constitutive matter in a body considered to be the same body through time. Thus, the (non-ensouled) living body cannot be an enduring individual for Descartes, according to this conception of a material individual. I bracket this problem as one to be dealt with elsewhere, and I turn instead to a second difficulty.

This is the problem of the role of teleology in Descartes' theory of life. For there is at least one juncture - and quite possibly more - at which teleology seems to enter in the conception of living bodies I have just developed as the conception to which I believe Descartes must be committed so as to vindicate his practice as a working scientist. But, to reiterate a well-known feature of Descartes' natural philosophy, he cannot make claims to teleology (taken specifically as a reflection of God's purposes) in natural philosophy, for God's purposes are opaque to us. And so, Descartes' theory of life may well rely upon illegitimate appeals to teleology. This difficulty will occupy the remainder of this paper. 


\subsection{Descartes' Theory of Life and Teleology}

In this section, my general approach is as follows. If any aspect of Descartes' theory of life requires an appeal to teleological purposes, then the second problem just identified arises. While there may be more than one way in which Descartes' theory of living bodies relies upon such purposes, all I need in order to proceed with my investigation of Descartes' theory of life and the related topic of method in his study of living bodies is one case where his theory relies upon appeals to teleological purposes. So I proceed by identifying just one such case and progressing to my proposed solution to the problem that arises for him as a result of this teleology.

Now it may seem that there is no difficulty since, despite appearances, Descartes does not rely upon teleology in his account of living bodies. He may rely heavily on functionality, but this is quite distinct from teleology. Shapiro (2003), as indicated above, provides a non-teleological account of the apparently normative concept of health, and to the extent that good health indicates continuing life, her account can extend to life as well. More pointedly, Deborah Brown (2013) explicitly offers a powerfully argued, non-teleological account of functions in Descartes' discussion of living bodies. I return to aspects of Brown's paper below.

However, Distelzweig argues that some of the uses of organic parts that appear in Descartes' medical writings rely upon final causal explanations of those parts. For at times, Descartes discusses parts and processes in terms of their uses in contributing to a function - that is, the parts are present because they serve the purpose of fulfilling certain functions. These are examples of illegitimate reliance upon teleology. Distelzweig discusses two such cases, namely Descartes' discussion of the number of membranes in the mitral valve of the heart in the fifth part of the Discourse (where his concern is with the human body and not the human composite) and his discussion of the senses in the sixth part of the Meditations. According to Distelzweig, in these cases Descartes holds that the body has specific parts or processes so as to be able to achieve at least some of the functions, which are definitive of them as living bodies. Ignoring the case of the senses (for this introduces the troublesome case of the human composite, which I will not address in this paper), the fact that Descartes employs teleological explanation in the case of the heart is problematic. For this example shows that in the case of the human body's heart and its mitral valves, a part and the processes that part undergoes, exist so as to realize a specific end or purpose. Thus a specific living activity of a subclass of living beings relies, in Descartes' analysis, upon a teleological explanation. If this is so, then at least some members of the domain of life (human bodies) are identified by at least one part and related process that are depicted teleologically. There may be other such examples, but as mentioned above, one is all I need for my purposes. Such teleologically-based explanations cannot be permitted on a Cartesian natural philosophy. So one of the effects, which go into the theoretical account I have provided of living bodies in Descartes' corpus, runs into difficulties.

Distelzweig further points out that teleological explanations might be grounded in one of a couple of different ways, neither of which is open to Descartes. The way 
I portray the nest of issues in what follow departs somewhat from Distelzweig's own way of laying out the conceptual terrain, but my portrayal is meant to bring out certain features of the terrain that I will need for what follows. I do not think that what I write here distorts Distelzweig's own understanding. The first way one might ground a teleological explanation relies upon the ontological priority of the whole to its parts such that the parts, systems and living functions and behaviors are there because of and to serve the purpose of preserving the whole animal. Distelzweig further argues that Descartes' theory of generation precludes this option, because according to his theory of generation, the parts come into being one after another and only after they have come into being does the whole begin to function. There are two ways in which this temporal priority of parts to whole might co-exist with an ontological priority of whole to parts. Both routes rely upon saying that there was always a plan of the whole, and that the plan included the fact that the whole would function so as to be self-preserving. The plan is what determines that the parts come into existence, one by one, and take on their finished, whole form. One way in which this general strategy could play out is to rely upon the Aristotelian substantial form, passed from male to female in sexual reproduction; this form carries with it the plan of the whole such that the parts form precisely in order to generate the whole and to serve the purpose of the self-preservation of the whole. Descartes' austere ontology precludes this approach; there can be no such form. The other way in which this general strategy could play out is to suppose that the plan is in the mind of a conscious builder of the whole such that the parts again are there because they serve the plan of creating a whole that is able to preserve itself through its life functions. This is the second option Distelzweig claims is closed to Descartes, for the conscious mind in the case of living bodies is God's - God intended for the parts, systems and their functions to be so-and-so in order to contribute to God's further purposes which may include the ability of a living body to preserve itself. And yet, Descartes unequivocally precludes making reference to God's intentions. It is this second option that I will interrogate in the remains of this paper.

Up to, and perhaps throughout, the early modern period, there were two general forms of teleology, even while there may also have been more forms that blended features of these two basic forms together. We may think of these as Platonic and Aristotelian forms of teleology.$^{30}$ In brief, according to Aristotelian teleology, some natural beings embody an immanent drive to fulfill purposes or achieve an end or goal that is their own end or goal, and they usually do so non-consciously or nonintentionally. Moreover, according to Aristotelian teleology, the intrinsic drive towards an end means that the efficient cause is end-directed; it is not the uniform, non-directed inertial motion we find in, for example, Descartes' conception of efficient cause. ${ }^{31}$ The Aristotelian model thus includes the belief that some natural beings have an intrinsic teleological nature such that explanations of their purposes

\footnotetext{
${ }^{30}$ For some helpful texts on thinking about different conceptual and historical issues in teleology/ final causation, see for example: Lennox 1985; Lennox 1992; Johnson 2005; Mayr 1992; and Detlefsen 2013.

${ }^{31}$ See Carriero 2005.
} 
can be grounded in the nature of the being itself, and not in something external to the being. According to Platonic, unnatural teleology, created beings have been designed by an external, conscious and intentional agent to fulfill the goals or ends of the agent; the craftsman model is paradigmatic. The Platonic model thus includes the belief that beings created by a craftsman may have no internal teleological nature such that explanations of their purposes must be grounded in claims about the intentions of its maker, and not in something internal to the being itself. ${ }^{32}$ As noted, there are blended forms of these two basic types of teleology. Aquinas, for example, believes that God creates natural beings with purposes in mind (Platonic teleology), but that he conveys these purposes in non-conscious form upon the natural beings such that they can share in God's purposes - albeit non-consciously - thus having an intrinsic teleological nature (Aristotelian teleology). ${ }^{33}$

Descartes' living bodies are ontologically only matter (taking on various sizes, shapes, speeds of motion and so forth) in lawful, inertial motion. For this reason, with respect to living bodies (the case of the ensouled human being may well be very different, of course), Descartes cannot rely upon Aristotelian teleology as the appropriate form of teleology to explain his reliance on teleological functions in his conception of life - wherever his functional accounts are, indeed, teleological, as in the case of the mitral valves in the heart.

Rather, if he is going to rely upon either of the forms of teleology under consideration, it would seem to have to be Platonic teleology: God built living bodies, he had purposes in mind with respect to those bodies and their parts when he built them (i.e. that they would function in specific ways), and those purposes are in the mind of God and in no way (unconsciously) held in the body. Bodies have no internal teleological nature, and so explanations about their purposes must make reference to the mind of God as the source and sole location of those purposes. In one sense, this is promising because Platonic teleology is wholly compatible with the ontology of living bodies as matter in lawful motion. But in another sense, this approach may seem doomed - and this is the source of Distelzweig's dismissal of this approach as a viable option for Descartes. That is, Descartes cannot seem to go this route because, according to Descartes, we do not know the purposes that God had in mind when he constructed the bodies of the world, and those purposes are to be found nowhere else but in the mind of God. Consequently, Descartes famously argues, we cannot rely upon those hidden purposes when investigating natural bodies:

When dealing with natural things, we will, then, never derive any explanations from the purposes, which God or nature may have had in view when creating them and we shall entirely banish from our philosophy the search for final causes. For we should not be so arrogant as to suppose that we can share in God's plans. We should, instead, consider him as the efficient cause of all things... (AT VIIIa, 15-6/CSM I, 202; emphasis added).

So Descartes seems to have no theory of teleology to rely upon in order to explain the functions of the living body - the functions which define living bodies - should

\footnotetext{
${ }^{32}$ For a development of these points and their impact on Descartes' conception of the mind-body human composite, see Detlefsen 2013.

${ }^{33} \mathrm{See}$, for example, Aquinas [1265-72] 1952-4.
} 
these functions be teleological. But there is at least one such case of a teleological function, i.e. the case of the mitral valves in the human body's heart. So Descartes relies upon teleology in this case, but seems to have no viable theory of teleology at hand to support this reliance. There's the problem.

But there is a part of my elaboration of the Aristotelian versus Platonic scheme given above that I think is too stark and understanding how it is so opens up a new possibility for thinking about teleology in Descartes. The overly stark characterization is in the claim that the Cartesian/Platonic model includes the belief that material bodies (ultimately consisting of only extended matter) that are created by God have no internal teleological nature and that thus, explanations of their purposes must be grounded entirely in claims about the God's intentions, and not in something internal to the bodies themselves. ${ }^{34}$ I don't think this is true, and I don't think Descartes could have held it to be true. Rather, I think Descartes is implicitly - and correctly - committed to the belief that wholly material bodies (where matter is extension) can, and in some way do, embody their builder's purposes. Specifically, for my current purposes, I think Descartes is implicitly - and correctly - committed to the belief that living bodies can, and in some way do, embody God's purposes such that we can make claims to those purposes without relying upon especially robust knowledge claims about purposes in God's mind. In the next section, I will provide textual and conceptual evidence for this claim as well as situating my claims about Descartes in historical developments about bodies and teleology.

\subsection{Natures and Teleology}

On the face of it, the claim that wholly material bodies on a Cartesian ontology can, in a sense, have internal ends communicated to them by God would seem to be dead in the water. It would seem to be indisputable that matter conceived of as only extension cannot, by its very ontological nature, embody purposes of a mind whether that be the mind of a human who builds a clock, for example, or the mind of God who builds a living body. Moreover, the claim that such matter can embody the purposes of a conscious mind may seem to fly in the face of Descartes' own enunciation of that non-purposive ontology of matter as found in Meditation VI, especially when we focus on the italicized portions of this passage (and breeze over the underlined portions, which I will discuss below):

[A] clock constructed with wheels and weights observes all the laws of its nature just as closely when it is badly made and tells the wrong time as when it completely fulfills the wishes of the clockmaker. In the same way, I might consider the body of a man as a kind of machine.... I can easily see that if such a body suffers from dropsy, for example, and is affected by the dryness of the throat which normally produces in the mind the sensation of

\footnotetext{
${ }^{34}$ Manning $(2012,252)$ notes that it is a "serious misreading" to interpret Descartes' extrinsic denominations, such as the health or illness of a human being, as entirely mind-dependent and in no way in the human being itself. I agree, though I do not focus on extrinsic denomination.
} 
thirst, the resulting condition of the nerves and other parts will dispose the body to take a drink, with the result that the disease will be aggravated. Yet this is just as natural as the body's being stimulated by a similar dryness of the throat to take a drink when there is no such illness and the drink is beneficial. Admittedly, when I consider the purpose of the clock, I may say that it is departing from its nature when it does not tell the right time; and similarly when I consider the mechanisms of the human body, I may think that, in relation to the movements which normally occur in it, it too is deviating from its nature if the throat is dry at a time when drinking is not beneficial to its continued health. But I am well aware that 'nature' as I have just used it has a very different significance from 'nature' in the other sense [as applied to the human composite]. As I have just used it, 'nature' is simply a label, which depends on my thought; it is quite extraneous to the things to which it is applied.... But by 'nature' in the other sense I understand something, which is really to be found in the things themselves; in this sense, therefore, the term contains something of the truth.

When we say, then, with respect to the body suffering from dropsy, that it has a disordered nature because it has a dry throat and yet does not need drink, the term 'nature' here is used merely as an extraneous label. However, with respect to the composite, that is, the mind united with the body, what is involved is not a mere label, but a true error of nature, namely that the body is thirsty at a time when drink is going to cause the body harm. (AT VII, 82-5/CSM II, 57-9; emphases added; trans alt.)

Focusing especially on the passages emphasized in italics, Descartes says explicitly that the supposed goal-directed 'nature' of clocks and human bodies considered solely in terms of their matter is a mere label, reflecting only purpose in my mind and is "is quite extraneous to the things to which it is applied". Material bodies are contrasted with mind-body composites, or human beings, in this passage, and human beings, unlike mere bodies, $d o$ have goal-directed natures. ${ }^{35}$ So the obvious question is: how possibly can I suggest that non-ensouled bodies can embody in their natures the purposes given to them by a conscious mind - how possibly can I suggest that wholly material bodies can have internal ends - when Descartes appears to deny precisely that?

To answer that question, let me distinguish among the following three topics: the natures of things and teleology; epistemology and teleology; and methodology and teleology. With respect to the natures of things and teleology, I make the further distinction between the ontologically basic nature of matter (ground floor metaphysics, if you will, or matter-as-extension in the case of Descartes) and the derivative nature of matter (the nature of visible physical bodies made up out of matter-as-extension). As Gary Hatfield has pointed out, Descartes himself acknowledges these two different kinds of natures, including that living bodies have natures qua visible living wholes (e.g. VIIIa: 53; IXb: 14). ${ }^{36}$

With respect to the natures of things and teleology, it is fruitful to ask whether or not a material being can embody, in its very nature, the purposes of a conscious mind (its maker, for example); can material beings possess internal ends? But that question can be further specified to ask two sub-questions: can a body considered

\footnotetext{
${ }^{35}$ Manning (2012) deals with this section of Meditation VI by focusing on the historical meaning of "extrinsic denomination" and "intrinsic denomination". My project, as will come clear, is a different one, and I believe it is, for the most part, compatible with Manning's approach. There is one point of departure from Manning's reading, which I address below.
}

${ }^{36}$ See Hatfield 2008, 416-17. 
solely as matter-as-extension have, in its very nature, internal ends?; and can a body of a clock or a dog, for example, made up out of matter-as-extension, have internal ends?

With respect to epistemology and teleology, it is fruitful to ask whether or not we can know the purposes of a thing, whether those purposes be embodied in a material being (internal ends) or whether those purposes be in a conscious mind and thus wholly external to the material being.

With respect to methodology and teleology, it is fruitful to ask whether there is a methodologically respectable way of relying upon appeals to purposes when explaining features of material beings (that is, in natural philosophy), whether those purposes belong to the natures of material beings or not, and whether we can definitively know what those purposes are or not. In this section, I deal with natures and teleology. In the next (final) section, I deal with the latter two issues of epistemology and methodology.

The italicized portions of the above-cited passage suggest that there is one kind of internal ends only, i.e. that which is found in the mind-body composite. Bodies without souls (or considered counter-factually in isolation from a soul, as in the case of the human body) do not possess such ends. Material bodies are, in their ontological nature, only extension of various sizes, shapes, moving in various directions and at various speeds, always in accordance with three basic laws of inertial motion. They have no goal-directed nature within themselves.

The underlined portions of the above-cited passage, however, rely upon bodies without souls possessing internal ends. If there were truly no difference in the nature of different clocks or different living human bodies, then the distinction between a clock that is "badly made and tells the wrong time" and a clock that "completely fulfills the wishes of the clockmaker" would be nonsensical; no such distinction could meaningfully be made. The same can be said for the distinction between a living human body and a dead human body. Descartes makes this strict parallel when he writes:

And let us judge that the body of a living man differs as much from that of a dead man as a watch or other automaton when it is in good working order and has in itself the corporeal principle of the movements for which it is instituted with all that is required for its action, [differs from] the same watch or other machine when it is broken and the principle of its action has ceased to act. (AT XI, 331/SV 21) 37 $^{37}$

Making the distinctions between a clock or a human body that works well/is healthy and alive and a clock or a human body that works poorly/is ill or dead relies upon those bodies possessing some kind of internal finality, or embodying the purposes of their makers, such that when those purposes are realized by the body,

\footnotetext{
${ }^{37}$ I have chosen to focus on living and dead humans, and their symmetry with working and broken watches, rather than to focus on the dropsy case because of the special, theological, context of the Sixth Meditation, where Descartes is trying to make sense of God's goodness in the face of apparent biological mistakes. While important (Brown 2013, 90ff), and I shall address this passage briefly below, I wish to keep the focus on the nature of living bodies and the ways in which understanding clocks can help us understand certain features of living bodies.
} 
the body works well/is healthy and alive, and such that when those purposes are not realized by the body, the body works poorly/is sick or dead. Or, to quote Descartes himself, a clock itself can "fulfill the wishes of the clockmaker", or fail to fulfill those wishes, which include the purposes the clock maker had in mind when building the clock, and the success or failure is a feature of the clock itself. To maintain the strict parallel at work in this passage, a living body can fulfill the wishes of God who made that body, or fail to fulfill those wishes, which include the purposes God had in mind when building the body, and the success or failure is a feature of the living body itself.

To approach the point from a different - and I think highly instructive - direction, consider the following example. Suppose I wish to make something that can convey to you, with a fair degree of precision, where the sun is in the sky relative to your location on earth. How do I do that? One way I can do it is by building a machine with two long sticks of slightly differing lengths that sweep around a circular surface such that when the sun is directly overhead of the spot on the equator where you find yourself, for example, the two sticks point straight up, and such that when the sun is either dipping down over the horizon or popping up over the horizon, the big hand points up and the little hand points down, and so forth. Similar descriptions can be given for a sun dial and other mechanisms built with the intention of telling time. I cannot ever convey to you where the sun is in the sky relative to your position on earth - that is, I can never tell you the time - by spilling one small drop of coffee on the floor in a room that has no access to natural light, no matter how insistently I say that producing a time-telling device was my purpose in spilling that single drop of coffee. The former machine can embody my purposes vis a vis timetelling, and it can convey those purposes to you in a way that the drop of coffee can never do. These facts remain true regardless of what I claim my intentions are. So: I have an intention (e.g. build something that tells the time) that requires I use material of specific sorts, organized in specific ways, and that once I build that thing such that it can successfully convey my intention to another conscious mind, then the object I have built embodies those intentions in a way that a drop of coffee, on this example, cannot do.

Where is the difference between these two material bodies, given that on a Cartesian ontology, the built machine and the drop of coffee both have the same, ontologically basic material nature (extension), and both inviolably obey the same laws of motion? Here is where the further distinction in the discussion of natures and teleology is helpful. For the temptation to say that material bodies are simply not the sorts of things that can embody internal finality, especially in light of the Sixth Meditation passage cited, can surely be said about material bodies considered in terms of their ontologically basic nature but this need not apply to bodies considered in terms of their derivative, built natures. For if there were no internal ends embodied in built machines (clocks built by humans or living bodies built by God), then no sense could be made of the idea of a clock being broken (i.e. failing to convey my purposes to you) when the hands don't move, or the idea of the body being defective when the mitral valves in the heart, for example, fail to open. Yet Descartes takes these ideas of deviation from well-working/health in the case of wholly 
material bodies as givens and as completely sensible (and he is right to do so). The underlined portions of the passage cite above establish this. ${ }^{38}$

Descartes recognizes these facts, and he does so specifically with respect to living bodies. For example, he claims that we humans could never build a bird, because we could never make matter that is appropriate for building a living bird (AT III, 163). Similarly, he claims we could never make ourselves a new body, for we cannot make such matter (AT VI, 148). In these claims, he recognizes that, despite the ground-floor ontological sameness of bird bodies, human bodies, clocks and so on, matter in its derivative forms can allow or not allow certain machines, presumably with certain purposes, to be built.

So the Sixth Meditation passage makes distinctions among three - not two different ways of thinking about bodies. One kind of body is the ensouled body of the composite, and these bodies have a goal-directed nature internal to them; they have internal finality of a unique sort grounded in their unique ontological nature as ensouled bodies. I will say no more about this special, and theoretically complicated, being in Descartes' ontology. There is a second kind of body that can be thought of in two different ways. This is the wholly material body, such as the human-built clock or the God-built living body. Thought of in terms of its groundfloor metaphysical nature, i.e. its constitutive matter-as-extension, such a body is in no way goal-directed; it is only matter in lawful inertial motion. But thought of in terms of its derivative physical nature, i.e. matter of a derivative kind structured in very particular ways, such a body can have internal ends, sharing in the purposes that a human or God had in mind when building it, even while this sort of internal finality may be very different from that found in the human composite. ${ }^{39}$

Let me be explicit about what I am and am not claiming about this third way of thinking about bodies, according to which wholly material bodies can have natures that include internal ends. Some conceptual-historical background will help here. Aristotelian ontology makes a difference in kind between living bodies and artifacts because the former have all four causes internal to them. Indeed, he even goes so far as to say that the formal cause (or substantial form), the efficient cause (or internal principle of change), and the final cause (the drive to a telos or end point) are one and the same cause within living bodies. In artifacts, by contrast, bodies themselves have only the formal and the material causes within themselves. Efficient and final causes are external to bodies, namely in the craftsman who builds the artifacts. According to one crude depiction, Cartesian mechanisms makes all bodies, including living bodies, into Aristotelian artifacts. But Aristotle is moved by a pretheoretical, and entirely common sense, understanding of artifacts, and that is that a craftsman can't build just anything out of any old matter. I cannot build a statue of a deer out of warm water; warm water does not have a suitable nature to be fashioned into a statue of a deer. Warm water is not the sort of matter that can bear

\footnotetext{
${ }^{38}$ For historical context that helps to bolster this idea, see Manning on extrinsic denominations (2012).

${ }^{39}$ On this point, I depart from a number of commentators. See Hoffman 1986 and 1999; Ariew 1983; Grene 1986 and 1991; Gueroult 1952; and Rodis-Lewis 1950.
} 
my purposes in this case. Aristotle has a theoretical way to account for this pre-theoretical and common sense intuition: no matter is completely un-informed in his view. Matter is always informed with some form or another. That is what makes warm water different, in kind, from marble. Ridding his ontology of this robust, Aristotelian conception of form may rob Descartes of this way of accounting for the pre-theoretical, and entirely common sense, intuition. But it does not dispense with the intuition in the first place. And it is an intuition that Descartes shares with Aristotle. This is shown by his acknowledgment that we could never build a living bird or make ourselves a new body, for we cannot make matter of the appropriate nature. No less than Aristotle (or any common sense, pre-theoretical view), Descartes believes that craftspeople must use material of a particular nature if they wish to build an artifact that can bear their ends. ${ }^{40}$

What I am claiming is the following. Descartes maintains the Aristotelian intuition about material natures that can embody a builder's ends - that can have internal ends, that is. This nature is presupposed by the distinctions he makes between a clock that works well and a clock that doesn't (indeed, to use my example, between a clock that is able, in the first place, to tell time and a drop of coffee that is not so able), and between a human body that is alive and one that is dead. Maintaining this intuition is perfectly sensible, and it would a be non-starter were Descartes to deny this pre-theoretical, common sense, understanding of bodies. For Descartes, this material nature capable of bearing internal ends is not to be found in the ontological essence of matter as extension but is rather to be found in the derivative nature of medium-sized matter shaped in various ways. However, I am not able, here, to further spell out the precise ontology of this derivative nature that has internal ends; indeed, given Descartes' rejection of Aristotelian ontology of informed matter, I am not sure his new austere ontology can allow for a derivative nature of material bodies with internal ends. ${ }^{41}$ Specifically, I am not sure his own conception of matter of three kinds, depending upon the relative size and speed of motion of their constitutive parts, is up to the task of accounting for the kind of matter needed to build living bodies. But he assumes bodies with such natures, and it is a sensible assumption. ${ }^{42}$

One final, crucial comment is in order. The question of God's making a body to fulfill certain purposes is distinct from, albeit intimately connected with, the question of the value or normative goodness of how well a body fulfills those purposes.

\footnotetext{
${ }^{40}$ For helpful material on Aristotle on many of these points, see Kosman 1987.

${ }^{41}$ Michael Della Rocca has suggested (in correspondence) that in creating the eternal truths, God has imposed natures on things, thereby endowing them with an intrinsic character. Indeed, in the case of God's creations, it might be more plausible to make the claim that his products can embody internal purposes. This would bolster my interpretation here, though my argument proceeds by analogy from the familiar case of human-made machines to the case of God-made machines.

${ }^{42}$ Tad Schmaltz has recently developed a convincing argument in favor of an unconscious, Aristotelian-type internal finality in human composites. See "Descartes's Critique of Scholastic Teleology" (manuscript). The current conception of intrinsic ends relies more upon a conscious agent's ability to signal her purposes, through very specific uses of matter, to another conscious agent. The current form thus leans more toward a Platonic form, albeit with the Aristotelian element of the purposes also being embodied in a non-conscious being.
} 
Brown draws our attention to the issue of normative value in her non-teleological account of bodily functions, underscoring that a non-teleological account of living functions has the benefit of accounting for life activities without God being culpable for mistakes in the body such as dropsy and death. ${ }^{43}$ My account here cannot similarly avoid this difficulty so easily, though this is not to say that there is therefore no solution to this problem. But the fact remains that Descartes does rely upon teleology in the case of the mitral valves. One way to explain that reliance is to couple his own strict parallel between clocks (for example) and living bodies with his embrace of the pre-theoretical acknowledgment that clocks can embody or fail to embody our purposes, and then conclude that for Descartes, living material bodies can similarly embody or fail to embody God's purposes. This may saddle Descartes with the problem of God's culpability, but the alternative would be to leave his teleological claims unexplained.

\subsection{Epistemology, Method, and Internal Ends}

Still, to complicate the current account and to set the stage for thinking about epistemology and teleology, as well as methodology and teleology, imagine someone who has never seen a clock before and has no previous knowledge of human-made time telling devices. ${ }^{44}$ Such a person may come across my large and heavy clock and wonder what it is and what it does. She may carefully observe it working over the course of several days and stumble across my true purpose in building it by noticing that the two sticks both point upwards when the sun is directly overhead or in the depths of night, and that the big stick points up and the little stick points down just when the sun rises or sets on the horizon and so forth. That person might come to understand that my clock will be very handy in conveying to her certain information about the position of the sun when she is in a basement room without access to natural light. Alternatively, this person may notice that my large and heavy clock is very handy in holding open the door to her basement room, and she might then conclude that it was made for this purpose. Indeed, the physical clock is made of materials that can serve this purpose too, though that was not my purpose when I built it.

Crucially, the clock is different from the living body for Descartes in the sense that the decoder of the clock can always ask me, or another human with knowledge of the true purpose that clockmakers have in mind, what internal ends the clock is supposed to embody according to its builder. Then the knowledgeable person can directly convey the purposes of the clockmaker. God's purposes are, according to Descartes, inscrutable and buried in the abyss of his wisdom. There is no asking God what he intended, and we cannot, without hubris, pretend to know his purposes,

\footnotetext{
${ }^{43}$ Brown 2013, 89-90.

${ }^{44}$ In Dialogues on Natural Religion, David Hume, of course, considers this question and provides a response that is especially interesting for the chaos theory, which I note is beyond the scope of this current project.
} 
even though they may seem to be on full display in the parts, processes and behaviors of the living bodies he has made (such as Gassendi claims: AT VII, 309; CSM II, 215). This brings us to the issues of teleology and epistemology, and teleology and methodology.

We have arrived at this point: conscious minds can convey purposes to bodies themselves, not in so far as we consider body as matter-as-extension, but in so far as we consider body as structured, visible machines made up out of matter-asextension. ${ }^{45}$ Still, in the case of living bodies for Descartes, we cannot know what purposes God might have conveyed to them when he created them, and so we cannot make use of teleology in our natural philosophy at all. This epistemological block seems to thwart my attempt to vindicate Descartes' teleologically laced conception of living bodies.

There is no doubt that Descartes' insistence that we cannot know God's purposes is meant to translate into the requirement that we never use teleological explanations in natural philosophy, including in our theories about living beings. But I think he goes too far in his precluding teleological explanations in natural philosophy, and I think there is a way he could have, and perhaps even should have made use of such explanations for a richer, more powerful natural philosophy. Specifically, he could have included teleological explanations on the basis of their being hypothetical explanations grounded in natural investigations of the internal ends found within living bodies themselves. It is true that Descartes explicitly rejects this methodological tool, but he may have been wrong to do so, and he loses so much more than he gains as a result of his rejection.

To set the stage for my suggestion, imagine again the person with no previous knowledge of human-made time-telling devices. She has decided that the purpose of my large and heavy clock is to prop open the door to her basement room. Suppose then, she comes across a small analogue pocket watch that resembles my clock in many ways though not in its size and weight, and that keeps time in perfect tandem with my clock. The similarity in most aspects of these two machines' structures, and in the behaviors they exhibit, are not lost on the imaginary observer. She then concludes that, while my clock does indeed do a wonderful job of holding open her door, there may well be a different purpose in the mind of the clock's builder - and embodied in the clock itself - than the one she originally attributed to the builder and clock. The more she comes across similar devices, the more she may investigate what may be the true purpose of my clock, at least as I intended it, and of similar machines; she may even latch upon my true purpose should she conclude that my clock is meant to tell people where in the sky the sun is. Of course, if she does not ask me my true purpose that I have embodied in the clock, she cannot claim that she

\footnotetext{
${ }^{45}$ Manning's $(2012,262)$ approach to the issue of health in the human and extension of this teleological notion to non-human living bodies, is to employ the historical conception of extrinsic denominations to attribute teleological notions of health and illness to human bodies themselves, and then extending these conclusions to animals due to their likeness to the living human body. My approach is to focus on the process of making machines, and the intentional imparting of purposes in that process, and to find a way we can depend upon that without depending upon knowledge claims about God's purposes.
} 
indubitably knows that she has latched upon my true purpose embodied in the clock. But the more evidence she gathers in the form of different examples of a wide variety of devices, which behave in a uniform way (i.e. successfully conveying the position of the sun relative to the person standing on the equator) despite all their material variety, the more she will be justified in thinking that her belief about my clock is probably a true belief; she may come to have what Descartes calls "moral certainty" that her belief is true.

This approach captures the way of hypotheses to which Descartes is very friendly starting at least from the time of the Discourse and texts attached to the Discourse. ${ }^{46}$ Descartes believes that first principles of philosophy set the confines for all of natural philosophy. But those principles radically underdetermine what could be true of bodies in the natural world. Most crucially, matter-as-extension and the three simple laws of motion, could have given rise to many different phenomena, most of which do not obtain in our actual world (e.g. AT VI, 64; CSM I, 144). And so the natural philosopher observes what is true of our world and proceeds to hypothesize (or suppose or guess) about the exact mechanisms, which might have given rise to the world we have - all the while respecting the first principles. This general approach to and reliance upon hypotheses carries through to Descartes' later works where he develops details of his approach to hypotheses more fully.

Historically, there have been two key directions in which thinking about hypotheses developed, indeed from Ancient times, and certainly throughout the seventeenth and eighteenth centuries as well. According to one approach - typified by Ptolemy in pre-modern thought and sometimes associated with 'save the phenomena' type explanations - hypotheses are posited merely because they are useful instruments, mere mathematical calculating devices especially useful for prediction and scientific practice. The aim with hypotheses, according to this approach, is not to propose a true account of the nature of things, since reaching true conclusions about the world is not necessarily relevant when formulating hypotheses according to this tradition, which focuses more pointedly on prediction. According to the second approach - typified by Aristotle in pre-modern thought and sometimes associated with causal explanations - hypotheses are posited in order to provide an explanation of how experienced effects might have come about. The aim is to give a true account of the nature of things, especially the causal nature of things ${ }^{47}$ In the Principles, Descartes comes down much more firmly on the side of hypotheses aiming for a true account of causes rather than on the side of hypotheses aiming simply to save the phenomena. ${ }^{48}$ His reasoning in the later work captures something

\footnotetext{
${ }^{46}$ This aspect of Descartes' method is far more complex - and interesting - than I make out here. For some work on Descartes and hypotheses, see Clarke 1989 and 2011; Lauden 1981; McMullin 2000 and 2008; Sakellariadis 1982; and Detlefsen forthcoming.

${ }^{47}$ For more on these two approaches to hypothesis, including the understanding of those such as Kepler and Galileo who believed these methods to be compatible, see McMullin 2000 and Friedman 2008, 71.

${ }^{48}$ There is a moment in the Principles when he seems to allow for the latter use of hypotheses, but a careful reading of this passage leaves open the distinct possibility that what is going on in the passage is Descartes' recognition of their lack of certainty, not their mere instrumentality.
} 
implicit, yet crucial, found in his letter to Morin of 13 July 1638 where he suggests that any hypothesis which accounts for multiple effects, including those not originally under investigation, is likely 'the true cause from which they [effects] result' (AT II, 199/CSMK 107). That is, should hypothesized causes explain a plethora of effects, including others not initially under investigation, then this simplicity and systematicity indicates that the hypotheses are probably true. He repeats this idea in the Principles (PP III, §43-4; AT VIIIa, 98-9/CSM I, 255).

This point connects with a significant feature of Descartes' account of hypotheses in the Principles, and this captures a development in scientific epistemology, which Desmond Clarke and Ernan McMullin have recently detailed. They note, that is, that some natural philosophers were moving away from treating less than certain knowledge in the form of hypotheses as merely speculative and thus unhelpful in scientific investigations. Rather, these natural philosophers believed that hypothetical claims carry important, even if not indubitably true, scientific information. That is, such philosophers were moving toward treating such knowledge as more or less probable, and therefore, more or less respectable. The degree of probability enjoyed by such hypotheses depends upon a number of factors, including, as suggested by Descartes, how simple and systematic they are ${ }^{49}$ Clarke thus points out that, throughout the 1600s, a new scientific epistemology emerged which allowed for a respectable, because not wholly speculative, category of the probable. Shortly after Descartes' time, this more palatable notion of probability is clearly articulated by Edme Mariotte in his Essai de logique (1678): 'An hypothesis of one system is more probable than that of another if, by assuming it, one explains all the phenomena or a greater number of phenomena more exactly, more clearly and with a stronger link with other known things...' ${ }^{50}$ Three quarters of a century later, Émilie Du Châtelet would provide a theoretical account of hypotheses and their role in science, which fully articulated this powerful new scientific eistemology. ${ }^{51}$ In his later work, Descartes seems to embrace such a conception of probability, retreating from an all-out claim to the certain truth of hypothesized causes (PP IV, §204; AT VIIIa, 327/CSM I, 289), even while claiming 'moral certainty' of their truth (PP IV, §205; AT VIIIa, 327-28/CSM I, 289-90). That is, while not metaphysically certain, Descartes' own posited hypotheses and conclusions derived from them are, in his view, not thereby mere arbitrary speculation. They are scientifically useful despite not being indubitably true..$^{52}$

(See PP III, §44; AT VIIIa, 99/CSM I, 255). The preponderance of Descartes' claims indicates that he takes the role of the natural philosopher to be the pursuit of true causes of phenomena.

${ }^{49}$ For accounts of Descartes' maturation on the relation between hypotheses and scientific epistemology, see Clarke 1989, chapter 7, and 2011 and McMullin 1990, 2000 and 2008. For a much earlier account of many of these themes recently developed by Clarke and McMullin, including a discussion of hypotheses, see Garber 1978.

${ }^{50}$ Mariotte 1678, 624.

${ }^{51}$ Du Châtelet 1740, chapter 4.

${ }^{52}$ For discussions on why Descartes' hypotheses are not merely speculative, see for example, McMullin 2008, 89 and Clarke 1989, 141-4. The latter makes a distinction between arbitrary and reasonable hypotheses, with reasonable hypotheses being assumptions, which can be systematized and unified into a system, ideally bound by laws. 
In the clock example above, I suggest a crudely parallel approach. And presumably the life scientist could employ the method of hypothesis posing and testing with respect to the purposes - the internal ends - that she finds in at least some living bodies. To put this in the context of the three teleological issues: God could have conveyed purposes upon living bodies, not with respect to their ground-floor metaphysical natures as matter-as-extension but with respect to their derivative natures vis-a-vis the sort and structure of their matter (natures and teleology), and although we can never know what those purposes are, we can develop beliefs about those purposes that are fairly likely true (epistemology and teleology), and we can do so through a method to which Descartes is very friendly, namely the method of positing hypotheses and seeing how they hold up to additional empirical data (method and teleology). That is, perhaps she could amass other example of hearts similar in structure to the human's heart to see if the mitral valve operates similarly therein. Or perhaps she could posit an hypothesis to test for other ends served by the heart's structure so as to determine whether or not that specific structure serves a number of other purposes beneficial to keeping the whole organism healthy and alive.

The merely probable, and not certain, nature of the purposes of teleological features in living bodies would not undermine Descartes' separation of living beings within a broader class of self-moving machines. Recall the general approach I suggested that Descartes takes to the study of living bodies. First, pre-theoretically, he identifies the kinds of bodies that belong to the class of living bodies, and these are plants, animals and human bodies. Then, he theorizes (or one can theorize on his behalf) about members of this domain. This theorizing can isolate (as argued in section I) a set of causes (heat and structure of a suitable nature) and a set of effects (a hierarchy of life behaviors), which are able to demarcate all and only these individuals. The job of the life scientist is to investigate these causes and effects, and in some cases (e.g. the mitral valves of the heart), features of the living being turn out to be explicable only by making appeal to a plan held by a conscious craftsman of those bodies, a plan that guided the construction of those bodies. The theoretical account of living beings turns out to be irreducibly teleological. Given Descartes' strictures against claiming knowledge of God's purposes with respect to the natural world, at best the natural philosopher could only hypothesize about God's purposes with respect to his plans for living bodies. She may be wrong about those purposes, but being so does not mean that Descartes loses the category of life tout court. It means simply that the natural philosopher will sometimes be mistaken in her explanations of some parts or processes that embody, in their very nature, internal ends - an embodiment that contributes to that which distinguishes the living from the nonliving. Moreover, one can use Descartes' own account of probability with respect to hypotheses to argue that the larger number of effects that can be explained by the supposed purpose, the greater the probability that the natural philosopher has hit upon the true teleological explanation of the behavior under investigation. One can never reach certainty, but a hypothesis can be thought to be more probably true with more and more effects accounted for by the hypothesis. This is in keeping with Descartes' participation in the historical emergence of a new scientific epistemology (recognizable to us today), according to which the probable is a respectable 
category and not to be discarded as merely speculative. So, far from posing a problem for Descartes by, for example, undermining the distinction between the living and the non-living, the role played by hypotheses regarding purposes is a scientifically powerful tool, which has the promise of spurring on empirical investigations of the behaviors of living things in order to grant greater and greater degrees of probability to the hypotheses posed.

Alas, Descartes rejects this approach - while we can hypothesize about God's purposes when engaged in moral philosophy, we cannot do so in natural philosophy (AT VII, 375; CSM II, 258). This is strongly implied by the nature of the hypothetical causes that Descartes specifies in the Principles - specific sizes, shapes and so forth of subvisible parts of matter (AT VIIIa, 325-6; CSM I, 288), and not God's plan with respect to the construction of the built machine. So, from Descartes' point of view, what I suggest above is illegitimate; we cannot use teleological explanations in so far as they are grounded in claims about God's purposes even as merely likely true beliefs in our explanations about the natural world, and so we cannot explain the teleological nature of (at least some) life activities by relying upon hypothetical claims to God's purposes as embodied in (at least some) living bodies. This is the core of Descartes' difficulty as I see it in his conception of living bodies: he does not exploit his scientifically powerful tool of the method of hypotheses in the realm of teleology and the life sciences. For without extending his friendliness to hypotheses regarding micro-mechanisms in natural philosophy to hypotheses about the internal ends of living bodies - for this would ultimately require making claims about God's likely purposes - it is impossible to make teleological claims about living bodies. But as I have shown in section II above, the theoretically robust conception of living bodies that one can develop on Descartes' behalf, and for which there is textual evidence in Descartes' corpus, depends upon making at least one teleological claim about living bodies. So some crucial aspects of what I take to be Descartes' theoretically robust explanation of living bodies that can reliably pick out all and only plants, animals, and human bodies, run afoul of Descartes' metaphysics of God's mind and what we can know of it.

Descartes does not reject hypothesizing about God's purposes tout court; he explicitly allows that we can engage in such an endeavor in the field of ethics by hypothesizes about God's purposes for us as moral beings. He does not, as we have seen, extend this use of hypotheses to the purposes of natural beings. To understand why, we should note that he offers two objections to using final causes in natural philosophy. His first objection is that it is hubris to suppose we know God's purposes; I have provided a way that Descartes could have side-stepped this worry given his friendliness to hypotheses. For in hypothesizing about God's purposes, we do not claim to know them. His second objection is that final causal explanations are the wrong kinds of explanations to offer in natural philosophy (AT V, 158; CSMK 341). ${ }^{53}$ But these sorts of causal explanations can co-exist with Descartes' favored form of explanation grounded in efficient causes, and they can co-exist within a

\footnotetext{
${ }^{53}$ For discussion of Descartes' reluctance to include final causes in natural philosophy, see Simmons 2001 and Hatfield 2008.
} 
Cartesian ontology of matter. One can hypothesize about God's likely purposes as he embodied them in living bodies, and these purposes can be compatible with a mechanical ontology of the material world, where all bodies are ultimately made up out of matter (as extension) in inertial lawful motion. One can further provide efficient causal explanations for how God's purposes are carried out in the living machines that he has built, as we witness over and over again in Descartes' reductionist explanations of life phenomena. It is true that precluding final causal explanations forces the natural philosopher to give efficient causal explanations if she is to engage at all in explanation - that is, if she is to engage in that crucial aspect of natural philosophy. But allowing final causal explanations does not thereby automatically preclude her giving efficient causal explanations as well. Descartes' overly cautious approach to the hypothesizing about God's purposes with respect to the natural world might have been sensible given the intellectual climate that forged him as a thinker, but it was unnecessary, and in going this route, he gave up on one crucially powerful tool for use within the sciences of life.

\section{References}

Ablondi, Fred. 1998. Automata, living and non-living: Descartes' mechanical biology and his criteria for life. Biology and Philosophy 13: 179-186.

Aquinas, Thomas. [1265-72] 1952-4. Truth. Trans. Robert W. Mulligan, S.J., James V. McGlynn, S.J., and Robert W. Schmidt, S.J. Chicago: Henry Regnery Co.

Ariew, Roger. 1983. Mind-body interaction in Cartesian philosophy: A reply to Garber. Southern Journal of Philosophy 21(supplement): 33-37.

Bitbol-Hespériès, Annie. 1990. Le Principe de Vie Chez Descartes. Paris: J. Vrin.

Brown, Deborah. 2013. Cartesian functional analysis. Australasian Journal of Philosophy 90(1): 75-92.

Canguihelm, George. 1965. La connaissance de la vie. Paris: J. Vrin.

Carriero, John. 2005. Spinoza on final causality. Oxford Studies in Early Modern Philosophy 2: $105-147$.

Clarke, Desmond. 1989. Occult powers and hypotheses: Cartesian natural philosophy under Louis XIV. Oxford: Clarendon.

Clarke, Desmond. 2011. Hypotheses. In The Oxford handbook of philosophy in early modern Europe, ed. Catherine Wilson and Desmond Clarke, 249-271. Oxford: Oxford University Press.

De Rosa, Raffaella. 2007. A teleological account of Cartesian sensations? Synthese 156: 311-336.

Delaporte, François. [1979] 1982. Nature's second kingdom: Explorations of vegetality in the eighteenth century. Trans. Arthur Goldhammer. Cambridge: MIT Press.

Des Chene, Dennis. 2000a. Life's form: Late Aristotelian conceptions of the soul. Ithaca: Cornell University Press.

Des Chene, Dennis. 2000b. Life and health in Cartesian natural philosophy. In Descartes' natural philosophy, ed. Stephen Gaukroger, John Schuster, and John Sutton, 723-735. New York: Routledge.

Des Chene, Dennis. 2001. Spirits and clocks: Machine and organism in Descartes. Ithaca: Cornell University Press.

Descartes, René. 1964-76. Oeuvres de Descartes, 11 vols, eds. C. Adam and P. Tannery. Paris: J. Vrin. Cited with abbreviation AT, followed by volume and page number. 
Descartes, René. 1985a. The philosophical writings of Descartes, 2 vols. Trans. John Cottingham, Robert Stoothoff, and Dugald Murdoch. Cambridge: Cambridge University Press. Cited with abbreviation CSM, followed by volume and page number.

Descartes, René. 1985b. The philosophical writings of Descartes, vol. 3: The correspondence. Trans. John Cottingham, Robert Stoothoff, Dugald Murdoch, and Anthony Kenny. Cambridge: Cambridge University Press. Cited with abbreviation CSMK, followed by page number.

Descartes, René. 1989. The passions of the soul. Trans. Stephen H. Voss. Indianapolis: Hackett Publishing Company. Cited by abbreviation SV followed by page number.

Descartes, René. 1998. The world and other writings. Ed. Stephen Gaukroger. Cambridge: Cambridge University Press. Cited by abbreviation SG followed by page number.

Detlefsen, Karen. 2013. Teleology and natures in Descartes' sixth meditation. In Descartes' meditations: A critical guide, ed. Karen Detlefsen, 153-176. Cambridge: Cambridge University Press.

Detlefsen, Karen. forthcoming. Du Châtelet and Descartes on the roles of hypothesis and metaphysics in natural philosophy. In Feminism and the history of philosophy, eds. Eileen O'Neill and Marcy Lascano. Kluwer Academic Press.

Distelzweig, Peter. 2015. The use of Usus and the function of Functio: Teleology and its limits in Descartes's physiology. Journal of the History of Philosophy 53: 377-399.

Du Châtelet, Émilie. 1740. Institutions de physqiue. Paris: Prault Fils.

Friedman, Michael. 2008. Descartes and Galileo: Copernicanism and the metaphysical foundations of physics. In A companion to Descartes, ed. Janet Broughton and John Carriero. Malden: Blackwell.

Fuchs, Thomas. 2001. The mechanization of the heart: Harvey and Descartes. Trans. Marjorie Grene. Rochester: Rochester University Press.

Garber, Daniel. 1978. Science and certainty in Descartes. In Descartes: Critical and interpretive essays, ed. Michael Hooker, 114-151. Baltimore: The Johns Hopkins University Press.

Garber, Daniel. 1992. Descartes' metaphysical physics. Chicago: University of Chicago Press.

Gaukroger, Stephen. 2000. The resources of Descartes' mechanist physiology and the problem of goal-directed processes. In Descartes' natural philosophy, ed. Stephen Gaukroger, John Andrew Schuster, and John Sutton, 383-400. London: Routledge.

Gaukroger, Stephen. 2002. Descartes' system of natural philosophy. Cambridge: Cambridge University Press.

Gaukroger, Stephen. 2010. Descartes' theory of perceptual cognition and the question of moral sensibility. In Mind, method and morality: Essays in honour of Anthony Kenny, ed. John Cottingham and Peter Hacker, 230-251. Oxford: Oxford University Press.

Grene, Marjorie. 1986. Die Einheit des Menschen: Descartes unter den Scholastikern. Dialectica 40: 309-322.

Grene, Marjorie. 1991. Descartes among the scholastics. Milwaukee: Marquette University Press.

Gueroult, Martial. 1952. Descartes selon l'ordre des raisons, vol. 2. Paris: Editions Montaigne.

Hall, T.S. 1970. Descartes' physiological method: Position, principles, examples. Journal of the History of Biology 3: 52-79.

Hatfield, Gary. 1993. Reason, nature, and God in Descartes. In Essays on the philosophy and science of René Descartes, ed. Stephen Voss, 259-287. Oxford: Oxford University Press.

Hatfield, Gary. 2008. Animals. In Companion to Descartes, ed. Janet Broughton and John Carriero, 404-425. Malden: Blackwell.

Hoffman, Paul. 1986. The unity of Descartes's man. The Philosophical Review XCV: 339-370.

Hoffman, Paul. 1999. Cartesian composites. Journal of the History of Philosophy 37: 251-270.

Johnson, Monte Ransome. 2005. Aristotle on teleology. Oxford: Oxford University Press.

Kosman, L.A. 1987. Animals and other beings in Aristotle. In Philosophical issues in Aristotle's biology, ed. Allan Gotthelf and James Lennox, 360-391. Cambridge: Cambridge University Press.

La Porte, Jean. 1928. La finalité chez Descartes. Revue d'Histoire de la Philosophie 2(4): 366-396. 
Lauden, Larry. 1981. Science and hypothesis: Historical essays on scientific methodology. Dordrecht: D. Reidel Publishing Company.

Lennox, James. 1985. Plato's unnatural teleology. In Platonic investigations, Studies in philosophy and the history of philosophy 13, ed. Dominic J. O'Meara, 195-218. Washington, DC: The Catholic University of America Press.

Lennox, James. 1992. Teleology. In Keywords in evolutionary biology, ed. Evelyn Fox Keller and Elisabeth A. Lloyd. Cambridge: Harvard University Press.

MacKenzie, Ann Wilbur. 1975. A word about Descartes' mechanistic conception of life. Journal of the History of Biology 8(1): 1-13.

Manning, Gideon. 2012. Descartes' healthy machines and the human exception. In The mechanization of natural philosophy, ed. Sophie Roux and Dan Garber, 237-262. Kluwer: New York.

Manning, Gideon. forthcoming. Extrinsic denomination. In Descartes Lexicon, ed. L. Nolan. Cambridge: Cambridge University Press.

Mariotte, Edme. 1678. Essai de logique. In Oeuvres, volume ii.

Mayr, Ernst. 1992. The idea of teleology. Journal of the History of Ideas 53(1): 117-135.

McMullin, Ernan. 1990. Conceptions of science in the scientific revolution. In Reappraisals of the scientific revolution, ed. David C. Lindberg and Robert S. Westman, 32-44. Cambridge: Cambridge University Press.

McMullin, Ernan. 2000. Hypothesis. In Encyclopedia of the scientific revolution: From Copernicus to Newton, ed. Wilbur Applebaum. New York: Garland Publishing Inc.

McMullin, Ernan. 2008. Explanation as confirmation in Descartes's natural philosophy. In A companion to Descartes, ed. Janet Broughton and John Carriero, 84-102. Malden: Blackwell.

Menn, Stephen. 2000. On Dennis Des Chene's physiologia. Perspectives on Science 8(2): 119-143.

Rodis-Lewis, Geneviève. 1950. L'individualité selon Descartes. Paris: J. Vrin.

Rodis-Lewis, Geneviève. 1978. Limitations of the mechanical model in the Cartesian conception of the organism. In Descartes: Critical and interpretative essays, ed. Michael Hooker, 152-170. Baltimore: Johns Hopkins University Press.

Sakellariadis, Spyros. 1982. Descartes's use of empirical data to test hypotheses. Isis 73(1): 68-76.

Schmaltz, Tad. Manuscript. Descartes's critique of scholastic teleology.

Shapiro, Lisa. 2003. The health of the body machine? Or seventeenth century mechanism and the concept of health. Perspectives on Science 11(4): 421-442.

Simmons, Alison. 2001. Sensible ends: Latent teleology in Descartes' account of sensation. Journal of the History of Philosophy 39(1): 49-75. 
Peter Distelzweig • Benjamin Goldberg

Evan R. Ragland

Editors

\section{Early Modern Medicine and Natural Philosophy}

望 Springer 


\section{Editors}

Peter Distelzweig

Department of Philosophy

University of St. Thomas

St. Paul, MN, USA

Evan R. Ragland

Department of History

University of Notre Dame

Notre Dame, IN, USA

\author{
Benjamin Goldberg \\ Department of Humanities \\ and Cultural Studies \\ University of South Florida \\ Tampa, FL, USA
}

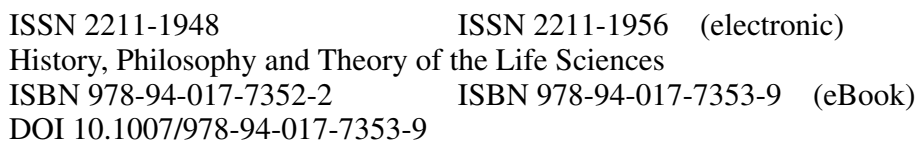

Library of Congress Control Number: 2015955134

Springer Dordrecht Heidelberg New York London

(C) Springer Science+Business Media Dordrecht 2016

This work is subject to copyright. All rights are reserved by the Publisher, whether the whole or part of the material is concerned, specifically the rights of translation, reprinting, reuse of illustrations, recitation, broadcasting, reproduction on microfilms or in any other physical way, and transmission or information storage and retrieval, electronic adaptation, computer software, or by similar or dissimilar methodology now known or hereafter developed.

The use of general descriptive names, registered names, trademarks, service marks, etc. in this publication does not imply, even in the absence of a specific statement, that such names are exempt from the relevant protective laws and regulations and therefore free for general use.

The publisher, the authors and the editors are safe to assume that the advice and information in this book are believed to be true and accurate at the date of publication. Neither the publisher nor the authors or the editors give a warranty, express or implied, with respect to the material contained herein or for any errors or omissions that may have been made.

Printed on acid-free paper

Springer Science+Business Media B.V. Dordrecht is part of Springer Science+Business Media (www.springer.com) 